\title{
PENTEL Actin-G Immunoelectrode: Immunoassay at the Tip of a Pencil
}

\author{
Dhanraj Rathod, ${ }^{[[a]}$ Susan Warren, ${ }^{[c]}$ Brian Seddon, $*\left[{ }^{[b]}\right.$ Baljit Singh, ${ }^{[b]}$ and Eithne Dempsey*[a, b]
}

\begin{abstract}
Here we present design and assay methodology of an actin-G immunoelectrode for the quantitation of muscle protein, actin. The immunoelectrode was assembled using a proprietary pencil material composed of a polymer-resin and graphite composite as an antibody support and electronic conductor. An effective immobilisation procedure for the capture antibody and surface blocking protein is cited based on a two-step physisorption chemistry. BSA coverage was demonstrated to reduce non-specific interactions to below $8 \%$ of the base polymer-graphite binding capacity. Immunoassays performed with the actin immunoelectrode utilise an $o$-benzoquinone-diimine electrochemistry which is formed insitu by interfacial peroxidase oxidation. Cyclic voltammetry data revealed the immunoelectrode surface to be porous to the diimine signalling molecule, while remaining inaccessible to macromolecules of the ELISA. The molecular structure and poly-functional nature of the immunoelectrode was further investigated using an anti-an-
\end{abstract}

tibody peroxidase conjugate. The findings suggest that capture antibody is randomly dispersed over the surface, exposing both Fc and actin binding sites. A saturation current density - concentration curve was analysed by Langmuir adsorption theory and an estimate for the antibody binding affinity derived $\left(K_{\mathrm{a}} \approx 1 \times 10^{5} \mathrm{M}^{-1}\right)$. The actin immunoelectrode was applied as a peroxidase detector in a double-antibody immunoassay. The electrode shows a dose-response characteristic which is most sensitive to actin over the concentration range $1-100 \mathrm{ng} \mathrm{mL}^{-1}$. Immunoelectrode sensitivity for actin is of the order of $5 \mathrm{nA} \mathrm{mm}^{-2} / \mathrm{ng} \mathrm{mL}^{-1}\left(10-100 \mathrm{ng} \mathrm{mL}^{-1}\right)$ with a limit of detection estimated at $10 \mathrm{ng} \mathrm{mL}^{-1}$ and measurement precision RSD $7.1 \%$ (100 $\mathrm{ng} \mathrm{mL}^{-1}$ actin). At higher concentrations of actin, $>100 \mathrm{ng} \mathrm{mL}^{-1}$ the immunoelectrode response is more complex. A high-dose hook characteristic becomes evident which arises from macromolecular steric interactions and other binding site limitations at the electrode surface.

Keywords: Pentel • Pencil • Graphite $\cdot$ Immunoelectrode $\cdot$ Actin $\cdot$ ELISA $\cdot$ Nonspecific Binding

\section{Introduction}

Actin is a ubiquitous structural protein of eukaryote cells with important roles in chemo-mechanical processes associated with motility and muscle contraction [1,2]. The molecule can transition between a $42 \mathrm{kDa}$ monomeric globular form (actin-G) and a filamentous structure under the control of actin-binding proteins. Cardiac muscle isoforms of globular actin are known and these were formerly applied as biochemical markers prior to troponin for heart diagnostic tests [3]. The occurrence of globular actin in blood is indicative of general tissue necrosis and considering the protein's abundance in muscle offers diagnostic value for the assessment of skeletal muscle damage.

Electronic devices possessing selective immunochemical receptors such as immunoelectrodes make ideal analytical instruments for the sensitive detection and quantitation of actin where muscle performance is being monitored. Immunoassay at the Tip of a Pencil was a research exercise intended to investigate assay development themes in connection with immunoelectrodes assembled with proprietary pencil-lead materials as alternatives to print or metal films. Practical aspects of the assay format and indeed the electrode system itself are not overriding issues in the current work, nor are method correlations for optimising a muscle actin diagnostic test. Rather, this preliminary research examines immuno-electrochemical methodology and concerns the advancement of operational aspects of immunoelectrode systems.

The study looks at the immunochemical characteristics of an anti-actin functionalised electrode (actin-G immunoelectrode) operating as a sensitive peroxidase detector based on $o$-benzoquinone-diimine redox electrochemistry. The work is largely concerned with aspects of actin reagent chemistry which is relevant to immunoelectrodeELISA use. Molecular stability and immunoreactivity of

[a] D. Rathod, E. Dempsey

Centre for Research in Electroanalytical Technologies (CREATE), Institute of Technology Tallaght (ITT Dublin)

Tallaght, Dublin 24, Ireland.

*e-mail: Eithne.Dempsey@ittdublin.ie

[b] B. Seddon, B. Singh, E. Dempsey

MiCRA-Biodiagnostics Technology Gateway Research Centre, CASH-Synergy Centre, Institute of Technology Tallaght (ITT Dublin)

Tallaght, Dublin 24, Ireland.

*e-mail: Brian.Seddon@ittdublin.ie

Baljit.Singh@ittdublin.ie

[c] S. Warren

Department of Materials, University of Oxford, Begbroke Science Park, Woodstock Road, Oxford, OX51PF, UK. 


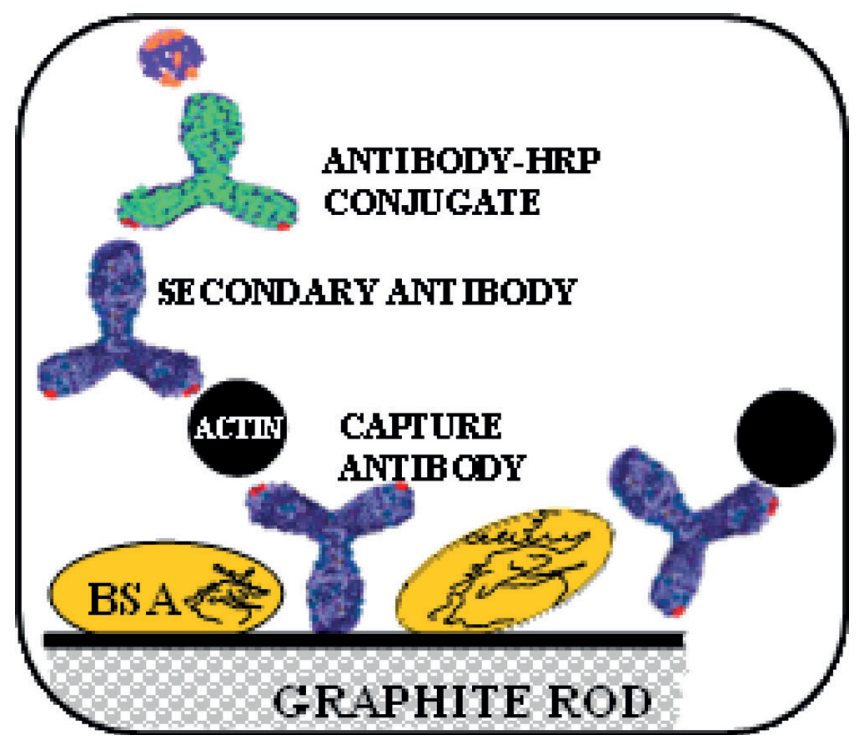

Fig. 1. Illustration of the actin immunoelectrode format exploited during ELISA. Anti-actin antibody (capture antibody) and BSA are irreversibly immobilised onto the polymer-graphite electrode surface. This assembly leaves inter-protein gaps which redox molecules can traverse. The scheme shows capture antibody bound actin, a polyclonal secondary antibody molecule and the signalling peroxidase conjugate prior to substrate introduction.

capture antibody (IgG) surfaces are paramount to the reliable operation of the electrode. These parameters are examined with reference to physi-sorption-immobilisation of the capture antibody for data collected during conjugate adsorption and actin assays.

Non-specific binding characteristics of the antibodyperoxidase conjugate towards the polymer-graphite and protein-modified surfaces, such as BSA monolayers, are communicated. Interest here lies in understanding and improving the efficiency of surface blocking in order to control random binding events while maximising access for the redox signalling molecule to the electrode.

The advantages and limitations of a secondary antibody detection strategy is also under scrutiny. Actin analysis makes use of a peroxidase-antibody conjugate which binds to a secondary antibody (polyclonal) as shown in the assay scheme of Figure 1. Inevitably, this aspect of the immunoassay introduces a further degree of complexity to the detection of actin, since the conjugate recognises both exposed $\mathrm{Fc}$ orientations of the capture antibody as well as the presence of specifically bound secondary antibody to captured actin. Electrochemical experiments are conducted to assess the level of responsiveness of the actin-G immunoelectrode to this peroxidase conjugate. Furthermore, the implications of conjugate background interference in quantitative actin analysis are discussed.

\section{Experimental}

\subsection{Materials}

Hi-polymer Super $0.5 \mathrm{~mm}$ HB re-fill pencil lead, C505 12 leads/box was supplied by Pentel Pencil Co, Japan. Film insulating polymer, poly(propylenecarbonate) $M_{\mathrm{n}}=$ $50 \mathrm{kDa}$ is an Aldrich product. Solvent for polymer dispersion was tetrahydrofuran, 99.5\% (LabScan Analytical Sciences). o-phenylenediamine, (OPD) $\geq 99 \% \mathrm{~m} / \mathrm{m}$ (Fluka). Hydrogen peroxide, $50 \%$ v/v (Sigma-Aldrich). All solutions were made up using deionised water (18 MQ) prepared with a PureLab water system (ELGA) and stored refrigerated until used. Immunoassay reagent solutions were prepared with phosphate buffer saline tablets (PBS, $\mathrm{pH}$ 7.4) purchased from Sigma Life Science. Horseradish peroxidase (HRP) assay solutions $(0.1 \mathrm{M}$, $\mathrm{pH}$ 6.0) were prepared from potassium phosphate monobasic $\left(\mathrm{K}_{2} \mathrm{HPO}_{4}\right) \geq 98 \%$ (Sigma) and potassium phosphate dibasic $\left(\mathrm{KH}_{2} \mathrm{PO}_{4}\right)$, ACS reagent $\geq 99 \%$ (Sigma), $\mathrm{pH}$ adjusted with $\mathrm{H}_{3} \mathrm{PO}_{4}, 85 \%$ (Aldrich) and included potassium chloride $(0.1 \mathrm{M}) \geq 99.0 \%$ (Sigma-Aldrich). Assay wash buffer used was PBS-Tween 20 (PBS-T) $\mathrm{pH}$ 7.4, $0.05 \% \mathrm{~m} / \mathrm{v}$, (Fluka). Bovine serum albumin (BSA) is employed for surface blocking and immuno-reagent stabilisation, $\geq 96 \%$ (Sigma). Actin from bovine skeletal muscle was supplied as a lyophilised solid $1 \mathrm{mg}$ (Sigma). Actin-G standards $\left(0 \mathrm{ng} \mathrm{mL}^{-1}-1000 \mathrm{ng} \mathrm{mL}^{-1}\right)$ were prepared in PBS-BSA $(0.1 \% \mathrm{w} / \mathrm{v} \mathrm{pH}$ 7.4) solutions from a stock of $1000 \mathrm{ng} \mathrm{mL}^{-1}$. Antibodies were purchased from Santa Cruz Biotechnology Inc. USA. Rabbit polyclonal anti-actin primary antibody $(200 \mu \mathrm{g}$ in $0.5 \mathrm{~mL}$ in PBS $\mathrm{pH}$ 7.4) was used for actin capture and as secondary antibody. Goat anti-rabbit-IgG peroxidase conjugate $(200 \mu \mathrm{g}$ in $0.5 \mathrm{~mL}$ in PBS pH 7.4) was used as the ELISA signalling label.

\subsection{Electrochemistry}

Electrochemistry studies were conducted using a CHI660c Electrochemical Workstation (CH Instruments, USA). For cyclic voltammetry measurements a single-compartment, three-electrode electrochemical cell $(8 \mathrm{~mL}$ capacity) was employed, with a platinum coil counter electrode $(0.5 \mathrm{~mm} \times 10 \mathrm{~mm})$ and a fritted $\mathrm{Ag} /$ $\mathrm{AgCl} \mid 3 \mathrm{M} \mathrm{KCl}$ reference. Working electrodes were composed of the polymer-graphite pencil leads sealed with a polycarbonate lacquer, leaving an exposed electrode tip of ca. $3 \mathrm{~mm}$. Cyclic voltammetry was performed at a scan rate of $100 \mathrm{mV} \mathrm{s}^{-1}$ over a fixed potential window of +0.1 to $-0.1 \mathrm{~V} \mathrm{vs} \mathrm{Ag} / \mathrm{AgCl}$. Prior to protein functionalisation, polymer-graphite electrodes were subjected to a mild anodic treatment in PBS (0.1 M, pH 6.0) electrolyte. This was achieved by scanning electrode potentials between 0 and $+1.0 \mathrm{~V}$ vs. $\mathrm{Ag} / \mathrm{AgCl}$ for 10 cycles, a process which enhanced the charge transfer characteristics of the carbon material towards redox molecules as well as confirming the low inherent electrochemistry of the composite graph- 
ite material. Electrochemical assays for peroxidase activity bound to polymer-graphite and immunoelectrode surfaces were performed in phosphate buffered solution (0.1 M, pH 6.0) containing $\mathrm{KCl}(0.1 \mathrm{M})$, and substrates; $o$ phenylenediamine $(1.0 \mathrm{mM})$ and hydrogen peroxide $(1.0 \mathrm{mM})$. Peroxidase activity was determined from the peak current of the $o$-benzoquinone diimine reduction wave at the immunoelectrode using cyclic voltammetry. ${ }^{4}$ Cathodic diimine and background currents were normalised for immunoelectrode area (geometric) and quoted as current density, $j=I / A$. In this work $j$ is reported in $\mathrm{nA} \mathrm{mm} \mathrm{m}^{-2}$ units (equivalent to $\mathrm{mA} \mathrm{m}^{-2}$ ).

\subsection{Surface Imaging}

SEM analysis was undertaken on vertical and transverse sections of Pentel pencil leads (JEOL LV-6390) to study the microscopic structure of the electrode surface. Transverse sections of Pentel pencil leads were analysed by mounting the leads horizontally on a carbon adhesive tab. Vertical sections were mounted in an amine-cured epoxy resin, which were ground and polished to a $1 \mu \mathrm{m}$ finish with diamond suspension. Epoxy mounted specimens were thin-film coated with Au/Pd using a SC7620 minisputter coater (Quorum Technologies) before electron microscope imaging.

\subsection{Pencil Electrodes}

The utility of commercial pencil leads as analytical electrodes was recognised several years ago with some of the earliest physicochemical characterisation studies in Japan on materials sourced from Mitsubishi and Pentel Pencil Companies [5,6]. These materials are manufactured from proprietary formulations of micron-graphite particulates and low-temperature thermoplastic resins which are extrusion processed into narrow rods. The surface composition of pencil leads may therefore be considered as a random distribution of graphite particles interspersed with electronically insulating polymer. Extruded graphite composites have since found applications as electrodes in different electroanalysis techniques, notably for studies on metal ions [7] and pharmaceutical molecules and biosensors $[8,9]$. Although their electronic, and in certain instances electrochemical properties of pencil materials are quite favourable, their poor tensile strength imposes practical restrictions.

Research in our laboratory has explored a series of Pentel polymer-graphite materials for electrodes in biosensor devices as alternative electronic supports to print and thin-film metals. It should be noted that in many cases the inherent electrochemical properties of commercial pencil leads define the extent of their usefulness. In this regard the Pentel graphite material reported in the present study is exceptional.

Electrodes were fabricated from a thermopolymergraphite material used in the manufacture of commercial fine pencil lead (Hi-Polymer HB, Pentel Pencil Company,

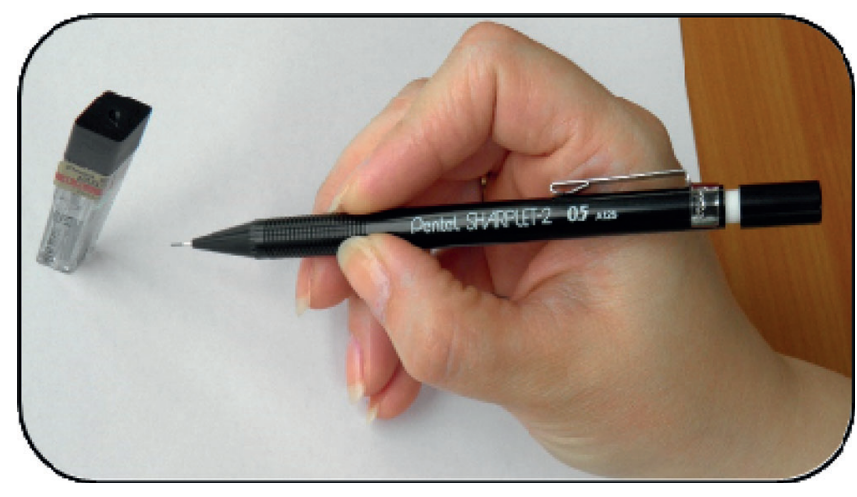

Fig. 2. PENTEL SHARPLET-2 0.5 mechanical pencil system with Hi-Polymer HB refill pencil leads employed in the construction of a single-measurement actin immunoelectrode.

Japan). The leads are supplied as re-fill rods for the SHARPLET-2 0.5 pencil system, Figure 2. Graphite rods for this pencil measure ca $0.55 \mathrm{~mm}$ diameter by $60.5 \mathrm{~mm}$ long and come supplied as 12 leads per box. They varied between $0.55 \mathrm{~mm}$ and $0.57 \mathrm{~mm}$ in diameter, $0.56 \pm$ $0.01 \mathrm{~mm}(n=10)$ as estimated by digital calipers. Electron micrograph data of resin-potted samples provide rod diameter estimates of $579 \mu \mathrm{m}(n=3)$. The electrochemical characteristics of the Hi-Polymer material were formerly investigated. ${ }^{5}$ This polymer-graphite composite possesses impressive chemical stability in aqueous media and excellent electrical conductivity $\left(R_{\mathrm{rod}}<5 \Omega\right)$. As an electrode the material has considerable utility, no inherent electrochemistry, and is stable for a broad range of applied electrolysis voltages $(> \pm 2 \mathrm{~V})$ and current densities (ca. $1 \mathrm{Am}^{-2}$ ). The material is known for its non-wetting - hydrophobic property, which can be overcome by anodic or oxidative chemical treatments. Owing to the organic polymer content of the Hi-Polymer HB leads, the electrode fails at high temperatures (etching at extreme current densities) and in certain organic solvents. These characteristics are not applicable in the present studies.

Pencil graphite rods were partially coated with a poly(propylenecarbonate) film to define the geometric area of the electrode. This was achieved by dispersing the poly$\operatorname{mer}\left(M_{\mathrm{n}} \approx 50 \mathrm{kDa}\right)$ in tetrahydrofuran $\left(100 \mathrm{mg} \mathrm{mL}^{-1}\right)$. The polycarbonate was applied to the rod using a capillary insertion technique. In this procedure, polymer-solvent $(20 \mu \mathrm{L})$ is injected into a capillary tube ( $1 \mathrm{~mm}$ dia.).

This is followed by the insertion and removal of a pencil rod. Stainless steel forcepts are used (HWC 11010 , Solingen, Germany). The length of rod protruding the capillary is estimated using digital calipers $(0.01 \mathrm{~mm}$ resolution). Graphite rods coated with polycarbonate were then heat cured at $60^{\circ} \mathrm{C}$ for 2 hours. This procedure left an insulation film covering the graphite rod of film thickness $<10 \mu \mathrm{m}$ with exposed lengths of $3.0 \pm 0.1 \mathrm{~mm}$, which defined an electrode surface area of $5.5 \pm 0.5 \mathrm{~mm}^{2}$. The polycarbonate coating, film thickness and electrode definition were examined by SEM imaging to confirm the extent of the polymer film surface. Of interest was the in- 

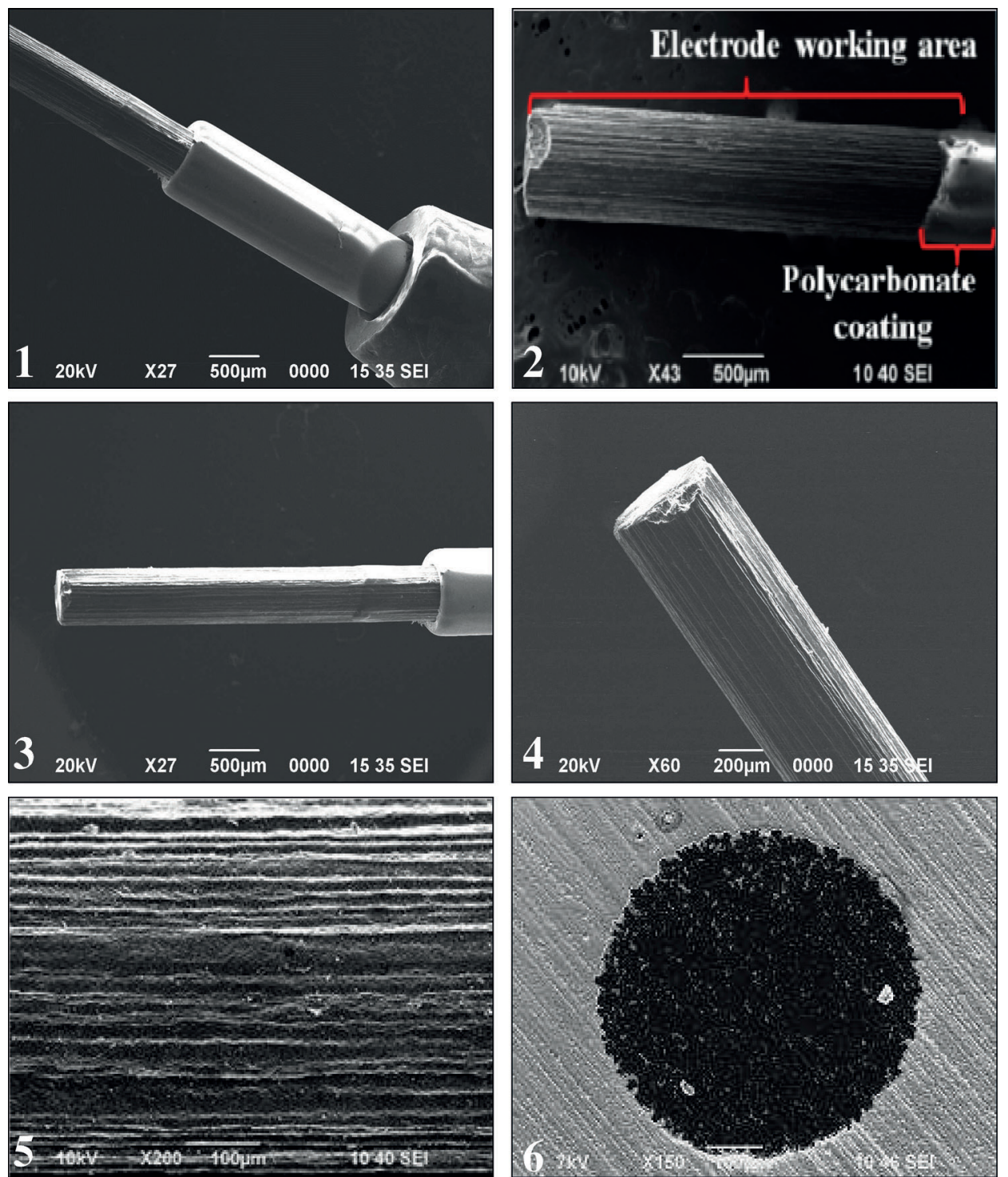

Fig. 3. SEM images of polymer-graphite lead composites: (1) Pencil lead held in the mechanical pencil system; (2) polymer-graphite rod with polycarbonate insulation; (3-4) shafts of pencil leads identifying edge deformations and surface striae; (5) Surface of the electrode at X200 magnification detailing the approx. $40 \mu \mathrm{m}$ microstructure; (6) epoxy-resin mounted graphite for rod diameter measurements.

tegrity of the insulation layer, its uniformity and adherence to the pencil lead (Figure 3). Poly(propylenecarbonate) coatings on graphite surfaces appear as glassy films. They offer durable thick-films, chemically stable in aqueous solution ( $\mathrm{pH} 5-8)$ with desirable electrical properties $\left(R_{\text {film }}>\mathrm{M} \Omega\right)$. The microscopic structure of the polymergraphite surface is revealed in the electron microscopy images of Figure 3. The pencil surface is composed of a regular pattern of undulations. This structure has an approximate peak-to-peak separation of $40 \mu \mathrm{m}$ and is an artefact of the lead manufacturing process. Surface roughness would thereby impart considerably greater microscopic area to the electrode than calculated by geometric measurements. In our estimations the microscopic surface of Pentel leads is of the order of $60 \%$ larger than the geometric figure suggests. Electrode area measurements by coulometry agree with the geometric calculation to within $3.5 \%$, since diffusion dependent charge is analysed.

\subsection{Actin-G Immunoelectrode}

This work outlines an effective physisorption technique for the capture antibody onto a polymer-graphite material used for pencil leads. The antibody coating procedure is similar to that for plate preparation in ELISA, where carbonate or phosphate buffer reagents are applied for efficient protein immobilisation onto polystyrene microwells. For immunoelectrodes it is essential that a coating protocol offers a stable and reproducible antibody monolayer for the immunoreaction with a specific antigen. Immunoelectrodes must not only have a support function for 
capture antibodies, but also offer an unrestricted pathway for redox molecules linked to the assay signalling mechanism. For this reason capture molecule layers and other surface modifications must remain porous to small molecules.

The first step in the immunoelectrode preparation involves immersion of polymer-graphite rods in a buffer solution of anti-actin capture antibody (anti-actin rabbit polyclonal antibody, $100 \mu \mathrm{L}$ of $1 \mu \mathrm{g} \mathrm{mL}^{-1}$ ) in PBS at pH 7.4. Antibody immobilisation was carried out at $25 \pm$ $1{ }^{\circ} \mathrm{C}$ for 12 hours. Electrodes were then "block-washed" with $5 \%$ BSA-PBS-T solution. The wash removes loosely bound antibody while filling vacant surface sites with inert protein. This initial treatment also leaves a loosely formed monolayer of capture antibody and BSA molecules adhered to the polymer-graphite surface, held largely by weak polar-ionic interactions. Such proteins are relatively easily removed from hydrophobic surfaces and as such unreliable in immunoassay applications. To enhance protein coating, a second step to the immobilisation procedure was found to be necessary. Actin antibody electrodes were allowed to air dry at $25 \pm 1{ }^{\circ} \mathrm{C}$ for 1 hour before being stored refrigerated at $4{ }^{\circ} \mathrm{C}$ for 24 hours prior to implementation. The combination of solution-phase physisorption, air drying and cold storage improves IgG and BSA adhesion to the polymer-graphite surface, allowing the immunoelectrode to undergo necessary vigorous washing steps during assays without significant loss of immunoreactivity. It is speculated that partial dehydration of the antibody monolayer on the pencil material leads to conformational changes which strengthens antibody-electrode interactions. Sets of electrodes coated with BSA alone were prepared in a similar manner by exposing the polymer-graphite material to a protein solution followed by washing with PBS-T and storing under refrigeration conditions. BSA electrodes were used to assess non-specific binding of reagents and as controls in actin immunoassays.

\subsection{Assays}

\subsubsection{Nonspecific Adsorption}

Adsorption characteristics of the anti-antibody-peroxidase conjugate onto BSA functionalised polymer-graphite surfaces were compared to the conjugate's interactions with the base polymer-graphite material [10,11]. BSA functionalised electrodes were incubated (set of 5 per vial) with buffer solutions of antibody-peroxidase conjugate $\left(200 \mu \mathrm{L}, \leq 1000 \mathrm{ng} \mathrm{mL}^{-1}\right)$ for 1 hour at $25 \pm 1{ }^{\circ} \mathrm{C}$. This was followed by dip-washing with PBS-T $0.05 \% \mathrm{~m} / \mathrm{v}$ (pH 7.4, 3 times). Similar treatments were followed for adsorption studies on the polymer-graphite material. The electrode was transferred to an electrochemical cell holding a platinum auxiliary electrode and silver reference electrode and electrolyte composed of phosphate buffer $\left(\mathrm{K}_{2} \mathrm{HPO}_{4} / \mathrm{KH}_{2} \mathrm{PO}_{4} 0.1 \mathrm{M}, \mathrm{KCl} 0.1 \mathrm{M}, \mathrm{pH} 6.0,2 \mathrm{~mL}\right)$ and peroxidase substrates, $o$-phenylenediamine $(1.0 \mathrm{mM})$ and hydrogen peroxide $(1.0 \mathrm{mM})$. After a period of one minute, cyclic voltammetry measurements were run to detect diimine formation and determine peroxidase activity at the electrode surface. Owing to the electrochemical reactivity of the $o$-phenylenediamine substrate, with significant electrooxidation beyond $+0.2 \mathrm{~V}$, electrode potentials in peroxidase assays were scanned between +0.1 and $-0.1 \mathrm{~V}$ vs. $\mathrm{Ag} / \mathrm{AgCl}$.

\subsubsection{Specific Binding}

The binding of anti-rabbit antibody-peroxidase conjugate to the actin immunoelectrode was investigated in a series of assays to elucidate capture antibody orientation. Here, immunoelectrodes and BSA electrodes were exposed to buffer solutions of antibody-peroxidase-conjugate $\left(200 \mu \mathrm{L}, \leq 1000 \mathrm{ng} \mathrm{mL}^{-1}\right)$ for 1 hour at $25 \pm 1^{\circ} \mathrm{C}$ (set of 5 per vial) after which electrodes were dip-washed with PBS-T (pH 7.4, 3 times) and the peroxidase activity measured by cyclic voltammetry. The electrochemical assay method applies BSA electrode controls with immunoelectrode measurements because of the concentration dependence of conjugate non-specific binding.

\subsubsection{ELISA}

Actin immunoassays with actin-G immunoelectrode as detector involved the following procedure: (i) actin immunoelectrode (set of 5 per vial), incubated with actin-G antigen $\left(200 \mu \mathrm{L}\right.$, standards: $\left.0-1000 \mathrm{ng} \mathrm{mL}^{-1}\right)$ for 1 hour at $25 \pm 1{ }^{\circ} \mathrm{C}$. This was followed by PBS-T dip-wash (3 times). (ii) actin-bound immunoelectrodes were then incubated with anti-actin antibody (secondary antibody) for 1 hour $25 \pm 1{ }^{\circ} \mathrm{C}$, and again washed with PBS-T. (iii) actin immunoelectrode is then incubated with anti-antibody peroxidase conjugate $\left(200 \mu \mathrm{L}, 1000 \mathrm{ng} \mathrm{mL}^{-1}\right)$ and again washed with PBS-T. Immunoelectrodes were then transferred to an electrochemical cell for peroxidase activity measurement. A set of BSA-functionalised electrodes as controls followed the same routine and were utilized for background assessment.

\section{Results and Discussion}

\subsection{Diimine Electrochemistry}

ortho-Phenylenediamine electrochemistry at polymergraphite electrodes is complex, displaying several electron transfer processes and chemical reactions leading to insitu generated redox species. Newly formed molecules themselves exhibit subtle oxidative electrochemistry. The anodic processes of $o$-phenylenediamine were researched previously in some detail. The oxidised species frequently cited is the reactive $o$-benzoquinone-diimine. This diimine molecule is electrochemically reduced to a di-amine or mono-imine $[7,8]$. In cyclic voltammetry the electro-oxidation of $o$-phenylenediamine in high-buffering phosphate electrolyte at pH 6.0 is well defined, Figure 4. Multiple anodic reactions are prominent; a primary peak is 


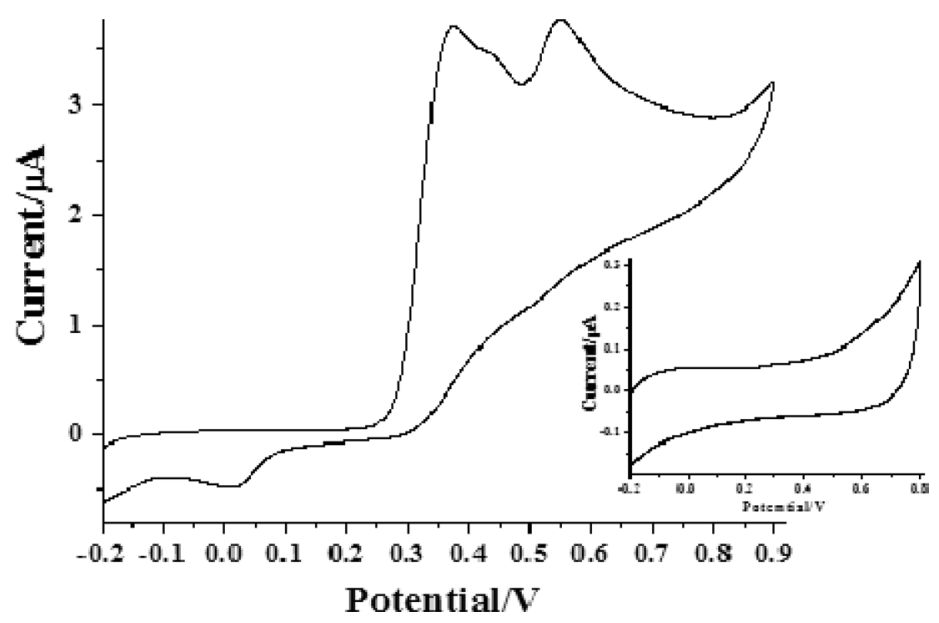

Fig. 4. Cyclic voltammetry of $o$-phenylenediamine in phosphate electrolyte. Electrolyte: phosphate buffer $\left(\mathrm{K}_{2} \mathrm{HPO}_{4} / \mathrm{KH}_{2} \mathrm{PO}_{4} 0.1 \mathrm{M}\right.$ $\mathrm{KCl} 0.1 \mathrm{M}, \mathrm{pH} 6.0, o$-phenylenediamine $(1.0 \mathrm{mM})$. Voltammetric scan $-0.2 \mathrm{~V}$ to $+0.9 \mathrm{~V}$ vs $\mathrm{Ag} / \mathrm{AgCl}, 100 \mathrm{mV} / \mathrm{s}$. Inset: Scan of phosphate electrolyte. Electrode: polymer-graphite pencil lead, $j_{\mathrm{pc}}$ diimine $=90 \mathrm{nAmm}^{-2}$, background $(-20 \mathrm{mV}), 20 \mathrm{nAmm}^{-2}$.

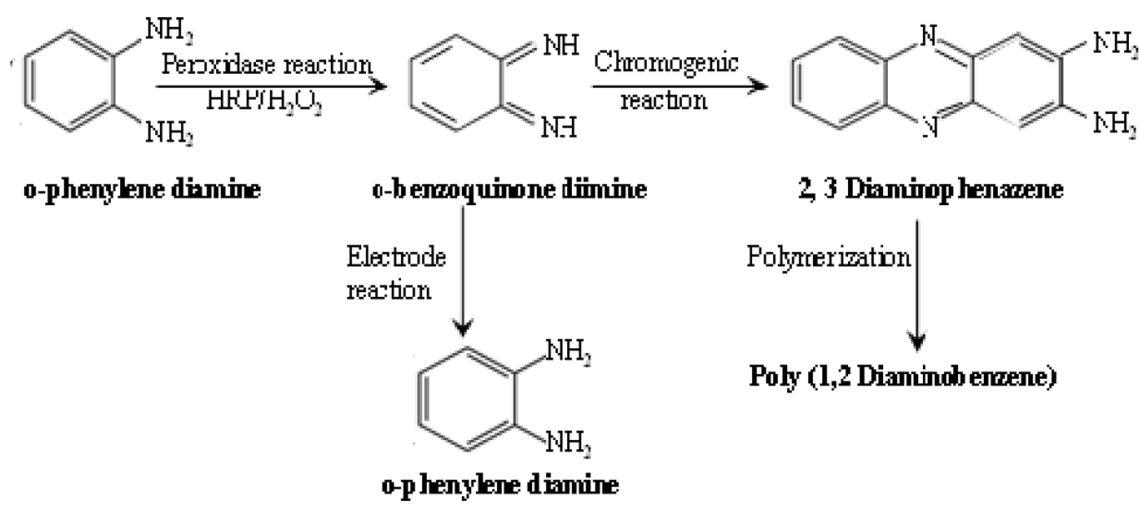

Fig. 5. Horseradish peroxidase and electrode reaction schemes for $o$-phenylenediamine substrate used for quantitative measurements of peroxidase activity at the immunoelectrode. The sequence oversimplifies outcomes since the diimine enzyme product may undergo hydrolysis and the electrode reaction may form other species to those of $o$-benzoquinone-diimine and $o$-phenylenediamine.

found around $E_{\mathrm{p}, \mathrm{a}}=+375 \mathrm{mV}$, with further electrochemistry seen at greater anodic potentials. Reverse scans display significantly less complexity, with a single and weak reduction process evident at $E_{\mathrm{p}, \mathrm{c}}=+9 \mathrm{mV}$. Further voltammetric characterisation of these electrode reactions indicated the molecule formed during the first electrode oxidation is the one detected in the cathodic scan. There is a marked difference between the anodic and cathodic limiting currents, $I_{\mathrm{a}} / I_{\mathrm{c}}=9.4$, which is indicative of the chemical instability of the $o$-benzoquinone-diimine. Hence, such follow-up reactions would ultimately lower the interfacial concentration of this diimine detected during the cathodic scan and therefore interfere with any diimine-linked electroanalysis.

Horseradish peroxidase and its antibody conjugates form $o$-benzoquinone-diimine via enzyme-catalysed oxidation of $o$-phenylenediamine with co-substrate hydrogen peroxide. This reaction is readily followed by voltammetry in mildly acidic aqueous solutions at polymer-graphite electrodes and BSA-functionalised electrodes. Pertinent reactions involving peroxidase, chemical and electro- chemical processes are shown in the schematic of Figure $5[12,13]$. A voltammetric scan range of $+0.1 \mathrm{~V}$ to $-0.1 \mathrm{~V}$ vs. $\mathrm{Ag} / \mathrm{AgCl}$ reference electrode, is chosen in these measurements to lessen the impact of electrooxidative formation of diimine, which interferes in peroxidase electroanalysis at $>+0.2 \mathrm{~V}$.

With peroxidase located at the electrode-electrolyte interface, catalytic turnover of substrate proceeds at enzyme-concentration limiting rates with the formation of $o$-benzoquinone-diimine. Once diimine is formed in this interfacial solution, the electrode detects the redox molecule by electroreduction. Cyclic voltammetry experiments on peroxidase-formed diimine at BSA electrodes feature characteristic cathodic waves formerly assigned to diimine reduction $\left(E_{\mathrm{p}, \mathrm{c}}=+6 \mathrm{mV}\right)$. A reverse scan reveals a diffusion-limiting anodic wave at $E_{\mathrm{p}, \mathrm{a}}=+66 \mathrm{mV}$.

This oxidation reaction is not obvious in the cyclic voltammetry of $o$-phenylenediamine and serves to emphasise the mechanistic differences between the peroxidase and electrode processes. The magnitude of cathodic currents is dependent on the concentration of peroxidase as well 

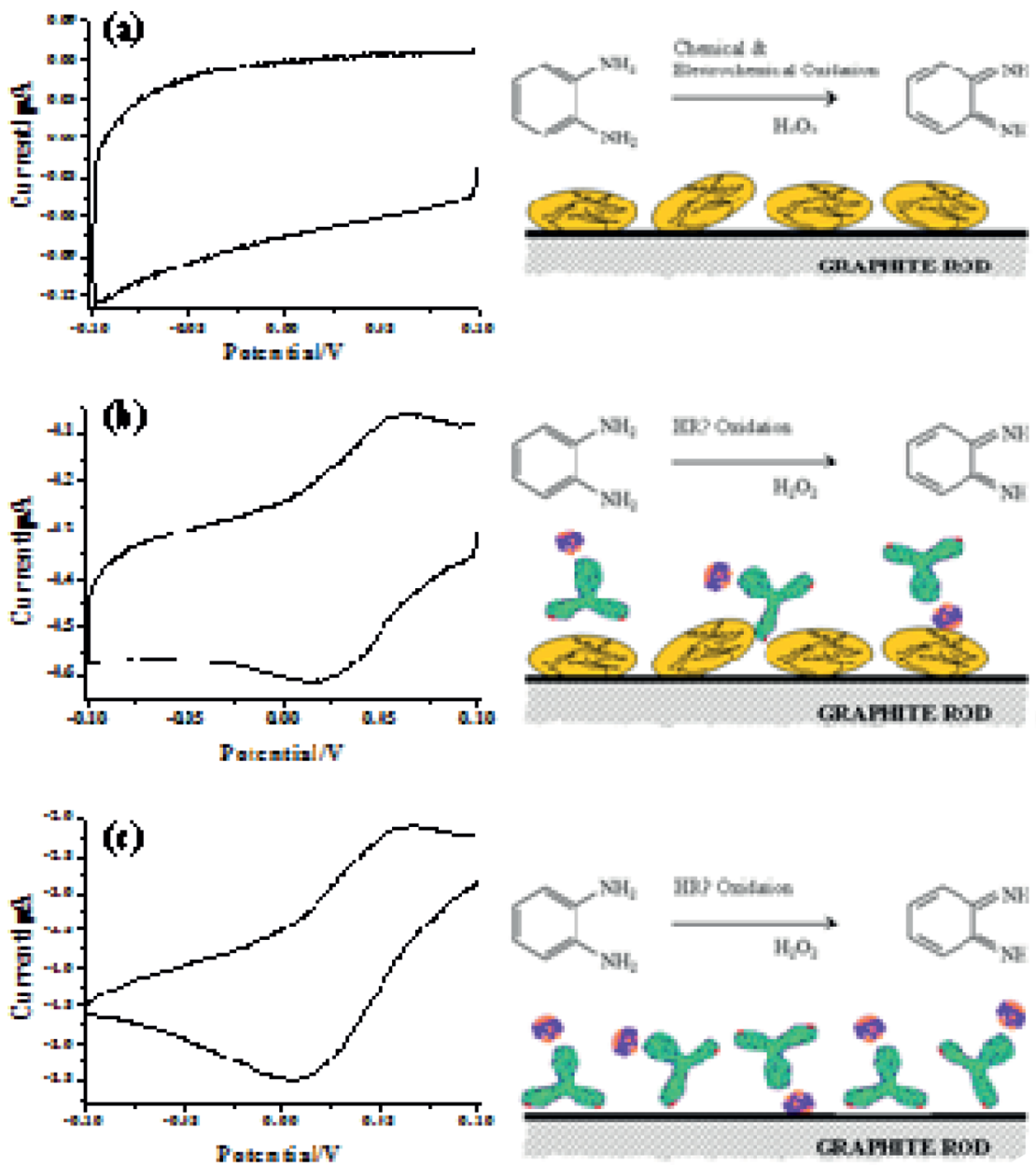

Fig. 6. Cyclic voltammetry study of non-specific binding at polymer-graphite electrodes. Scan: $+0.1 \mathrm{~V}$ to $-0.1 \mathrm{~V}$ vs. $\mathrm{Ag} / \mathrm{AgCl}$, $100 \mathrm{mV} / \mathrm{s}$. (a) Substrate background (o-phenylenediamine-hydrogen peroxide in phosphate electrolyte, $\mathrm{pH} 6.0$ ) at a BSA electrode; $j$ $(-20 \mathrm{mV}) 24.8 \mathrm{nA} \mathrm{mm}^{-2}$ (b) peroxidase conjugate adsorption at a BSA electrode; and (c) peroxidase conjugate adsorption at a polymer-graphite electrode. Right: electrode illustrations.

as reaction time. For BSA functionalised electrodes with conjugate in the interfacial solution, current densities realised after a $1 \mathrm{~min}$ peroxidase reaction are of the order of $1800 \mathrm{nAmm}^{-2}(n=5, R S D 5.3 \%)$. In the absence of peroxidase, cathodic currents correspond to the substrateelectrolyte background, $j_{\mathrm{p}}=25 \mathrm{nA} \mathrm{mm}^{-2} \quad(n=3)$. The origin of such electrolytic currents relate not only to the electrooxidation of $o$-phenylenediamine and electrochemistry of surface protein molecules, but also to the rate of chemical formation of $o$-benzoquinone-diimine at $\mathrm{pH} 6.0$ over the measurement period.

\subsection{Conjugate Adsorption}

Adsorption of the anti-antibody-peroxidase-conjugate onto polymer-graphite and BSA-functionalised surfaces was investigated to establish the degree of non-specific binding to these materials $[10,11]$. Polymer-graphite and BSA electrodes were exposed to solutions of the antibody-peroxidase conjugate $\left(\leq 1000 \mathrm{ng} \mathrm{mL}^{-1}\right)$ for 1 hour at $25 \pm 1^{\circ} \mathrm{C}$. Electrodes were then passed through a phos- phate wash prior to electrochemical peroxidase assay with $o$-phenylenediamine to quantify surface-bound conjugate.

$o$-benzoquinone-diimine electrochemistry originating from electrode-adsorbed peroxidase presented characteristics similar to those of the solution phase reaction, i.e. a redox couple is identified with a discernable diffusion limiting cathodic wave and a reverse oxidation wave (Figure 6). Current densities $\left(j_{\mathrm{pc}}\right)$ measured with these electrodes are typically $>1 \mu \mathrm{Amm}^{-2}$, e.g. mean $j_{\mathrm{pc}}=$ $1109 \mathrm{nA} \mathrm{mm}^{-2}(n=3, R S D 10.4 \%)$, as a consequence of strong protein-material interactions adhering peroxidase to the electrode. The diimine reduction potential $\left(E_{\mathrm{pc}}\right)$ assigned to this cathodic process appears at $+5 \mathrm{mV}$ ( $\Delta E$ of $55 \mathrm{mV})$. This voltammetry contrasts with that for BSA electrodes where cathodic currents are much lower, $89 \mathrm{nA} \mathrm{mm}^{-2}(n=6, \quad R S D \quad 19.8 \%)$ and $E_{\mathrm{pc}}$ typically $+15 \mathrm{mV},(\Delta E$ of $45 \mathrm{mV})$. For an equivalent conjugate exposure time, BSA immobilisation on polymer-graphite electrodes leads to a significant diminution of diimine currents ( $>10$ fold) when compared to the polymer- 
Table 1. Data for specific binding assays of the antibody peroxidase at the actin immunoelectrode. Current densities, $j_{\mathrm{p}}$, are calculated from cathodic current and electrode area estimates. Background is non-specific peroxidase activity at BSA electrodes. Corrected $j_{\mathrm{p}}$ diimine signal with background subtraction.

\begin{tabular}{clllllll}
\hline Conjugate $C(\mathrm{ng} / \mathrm{mL})$ & Conjugate $j_{\mathrm{p}}\left(\mathrm{nA} \mathrm{mm}^{-2}\right)$ & $n$ & $R S D(\%)$ & Background $j_{\mathrm{p}}\left(\mathrm{nA} \mathrm{mm}^{-2}\right)$ & $n$ & $R S D(\%)$ & Corrected $\left.j_{\mathrm{p}}(\mathrm{nAmm})^{-2}\right)$ \\
\hline 0 & 24.0 & 4 & 21.4 & 24.8 & 3 & 35.1 & -0.8 \\
10 & 57.4 & 5 & 11.7 & 21.0 & 5 & 16.2 & 36.0 \\
100 & 507 & 5 & 14.5 & 28.8 & 5 & 20.8 & 478 \\
300 & 1463 & 4 & 10.5 & 18.5 & 5 & 17.8 & 1445 \\
500 & 1619 & 5 & 10.1 & 28.2 & 5 & 26.2 & 1591 \\
700 & 1959 & 3 & 5.7 & 30.5 & 5 & 22.3 & 1929 \\
900 & 2655 & 5 & 6.4 & 32.0 & 5 & 25.2 & 2622 \\
1000 & 2685 & 5 & 17.9 & 60.8 & 3 & 21.2 & 2624 \\
\hline
\end{tabular}

graphite material. The BSA electrode response to peroxidase activity is a mere $8 \%$ of that of the exposed polymer-graphite electrode (background is $2 \%$ ). These results illustrate classic nonspecific adsorption effects encountered with almost all polymer and metal surfaces in electrode-based immunoassay. The electrochemical data is also a quantitative measure of peroxidase conjugate surface concentration and demonstrates the capacity of BSA molecules to induce blocking properties on the Pentel HB pencil material $[10,11,14]$. A current-concentration response of the BSA electrode to peroxidase conjugate was further elucidated by cyclic voltammetry. Table 1 shows the sensitivity of the electrode to surface peroxidase activity for a series of conjugate concentrations $\left(0 \mathrm{ng} \mathrm{mL} \mathrm{mL}^{-1}-1000 \mathrm{ng} \mathrm{mL}^{-1}\right)$. The baseline currents for this electrode lay around $25 \mathrm{nAmm}^{-2}\left(0 \mathrm{ng} \mathrm{mL}^{-1}\right)$. Furthermore, cathodic currents remain near to background levels for much of the entire concentration series $\left(10 \mathrm{ng} \mathrm{mL}^{-1}\right.$ $500 \mathrm{ng} \mathrm{mL}^{-1}$ ), gradually rising as conjugate levels become $>500 \mathrm{ng} \mathrm{mL}^{-1}$. Current density at the BSA electrode extends to $60 \mathrm{nA} \mathrm{mm}^{-2}$ for conjugate concentrations approaching $1000 \mathrm{ng} \mathrm{mL}^{-1}$ - i.e. a three fold increase on the background and further evidence of the exceptional blocking efficiency of the inert protein layer. The origin of nonspecific adsorption of the peroxidase conjugate is predominently weak ionic interactions created between the conjugate protein and the BSA monolayer. There is also the possibility of hydrophobic associations at enlarged, open sites on the polymer-graphite electrode. The electrochemical data allows speculation on the nanostructure of the BSA electrode surface. This could be seen as an arrangement of closely packed protein molecules restricting access of bulky antibody conjugate molecules to the polymer-graphite surface, while allowing detection of $o$-benzoquinone-diimine redox molecules.

In fact the surface of the actin-G immunoelectrode is viewed as a scattered assembly of actin capture antibody interspersed with immunochemically inert BSA molecules covering an electrically conducting support. In this model, the surface would compose of binding sites specific for the antigen, along with $\mathrm{Fc}$ regions which are recognised by anti-antibodies. The immunoactivity of the electrode towards antibodies was demonstrated with an anti-antibody-peroxidase probe. This study used a rabbit polyclo-

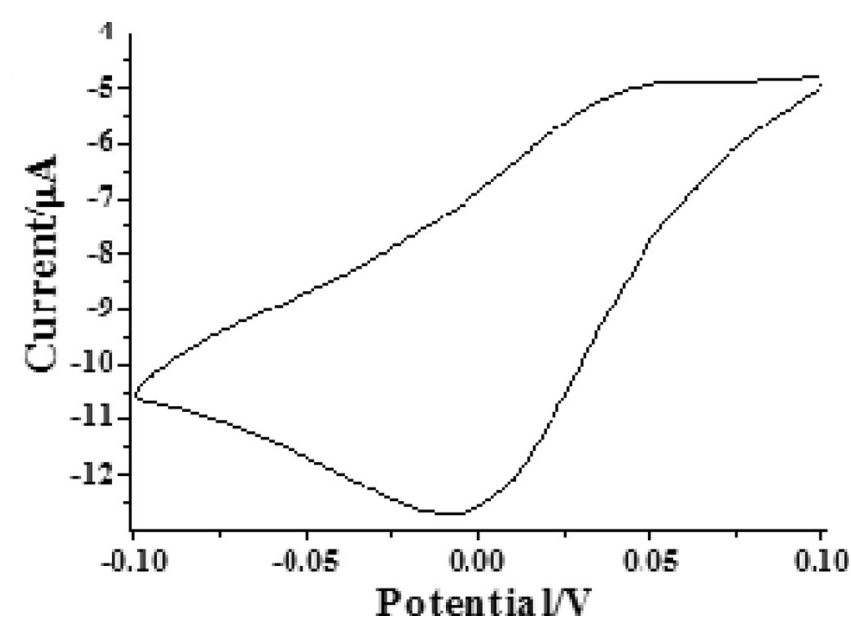

Fig. 7. Cyclic voltammetry study of specific binding of peroxidase conjugate $\left(1000 \mathrm{ng} \mathrm{mL}^{-1}\right)$ at the actin immunoelectrode. Conditions: see specific binding assays. Scan: $+0.1 \mathrm{~V}$ to $-0.1 \mathrm{~V}$ vs. $\mathrm{Ag} / \mathrm{AgCl}, 100 \mathrm{mV} / \mathrm{s}$.

nal capture antibody and anti-rabbit conjugate. The latter binds specifically to the capture antibody. Detection of diimine electrochemistry after exposure of the immunoelectrode to the conjugate indicates the presence of surface bound peroxidase and is therefore indicative of available Fc sites on the electrode. Figure 7 shows a typical electrochemical response of the actin immunoelectrode to the exposure of the anti-antibody conjugate. Cyclic voltammetry identifies an intensified cathodic signal $\left(E_{\mathrm{pc}} \approx\right.$ $-10 \mathrm{mV})$.

The diimine $j_{\mathrm{pc}}$ of the actin immunoelectrode was $2685 \mathrm{nA} \mathrm{mm}^{-2}$ when incubated with a conjugate concentration of $1000 \mathrm{ng} \mathrm{mL}^{-1}$.

The equivalent measurement with a BSA electrode yielded currents of $61 \mathrm{nA} \mathrm{mm}{ }^{-2}$ where no specific binding is realised. Clearly peroxidase conjugate displays a stronger association for the immunoelectrode, elevating peroxidase surface concentration over that observed for nonspecific adsorption at BSA layers, or indeed the pencil material (polymer-graphite, $j_{\mathrm{pc}}=1109 \mathrm{nA} \mathrm{mm}^{-2}$ ).

Since the anti-antibody recognises Fc protrusions on the immobilised capture molecule, the electrochemical data is evidence that the electrode is immunochemically 


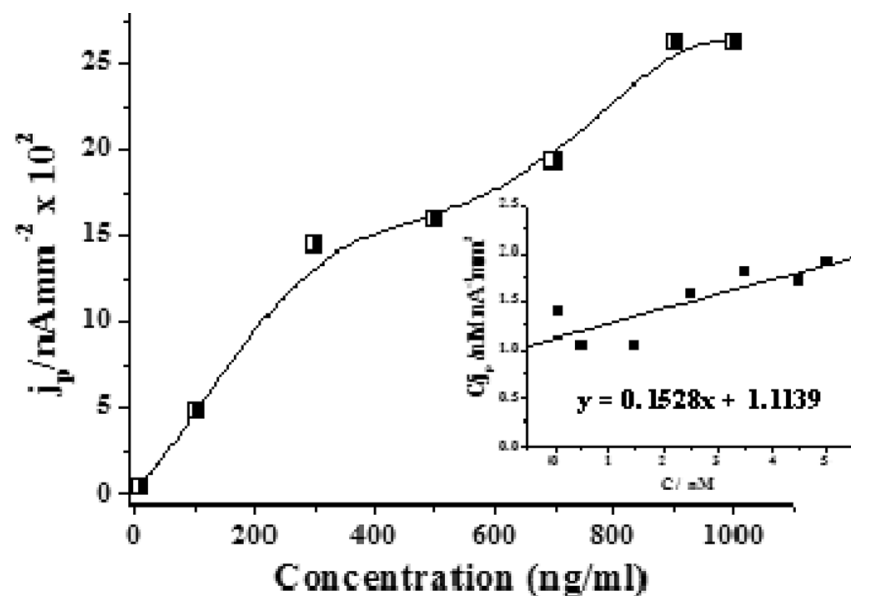

Fig. 8. Dose-response plot for the actin immunoelectrode response to peroxidase conjugate concentration. Voltammetry data from Table 1. Inset: Langmuir treatment of conjugate adsorption data. $C / j_{\mathrm{p}}$ vs. $C$ plot, where partial surface coverage is equated to surface concentration of peroxidase and the diimine current density, i.e. $\theta=j_{\mathrm{p}} / j_{\mathrm{p}, \max }$. Conjugate concentration is plotted in $\mathrm{nM}$ units.

active and potentially highly heterogeneous in terms of binding characteristics.

The affinity of the conjugate to this surface exhibits a dose-response characteristic over the concentration range $0-1000 \mathrm{ng} \mathrm{mL}^{-1}$ (Figure 8 ). The immunoelectrode is responsive to peroxidase conjugate concentration down to $10 \mathrm{ngmL}^{-1}: j_{\mathrm{p}}=36 \mathrm{nA} \mathrm{mm}^{-2}(n=5, R S D 11.7 \%)$. The magnitude of the cathodic current eminating from surface-bound peroxidase increases sharply to $300 \mathrm{ng} \mathrm{mL}^{-1}$ then more gradually leading to the appearance of signal saturation $>900 \mathrm{ng} \mathrm{mL}^{-1}$, where the immunoelectrode $j_{\mathrm{p}}$ approaches values exceeding $2600 \mathrm{nA} \mathrm{mm}^{-2}$. The form of this curve resembles a molecular adsorption isotherm displaying a binding limitation for the interaction of the conjugate with the surface, perhaps owing to binding site saturation or through steric hindrance. The curve also hints at the formation of multi-molecular layers, with an initial saturation at $500 \mathrm{ng} \mathrm{mL}^{-1}$.

By its nature, the actin immunoelectrode is heterogeneous and bulky protein-protein interactions are likely during any surface complexation process. A Langmuir treatment of conjugate adsorption could only be expected to yield estimates of maximum immunoelectrode output, $j_{\text {pmax }}$, or a rudimentary of the affinity constant, $K_{\mathrm{a}}$ for the capture antibody-conjugate immunoreaction.

Langmuir isotherm [15]:

$\theta=\frac{k_{2} C}{k_{1}+k_{2} C}$

Where, $C$ is the molar concentration of solution peroxidase conjugate $\left(M_{\mathrm{r}} \approx 200 \mathrm{kDa}\right), k_{1}$ is the desorption rate coefficient and $k_{2}$ the adsorption rate coefficient for conjugate sorption at the immunoelectrode. Writing surface coverage, $\theta$ in terms of surface concentration $\Gamma$ of perox- idase conjugate, $\theta=\Gamma / \Gamma_{\max }$. And equating, $\Gamma$ to the peroxidase reaction rate and diffusion current at the immunoelectrode for the diimine reduction $\left(\Gamma_{\text {dimine }}=k_{\text {cat }} . \Gamma_{\mathrm{HRP}} t\right.$, $K_{\mathrm{mOPD}} \approx 50 \mu \mathrm{M}$ and $\left.C_{\mathrm{OPD}} \gg K_{\mathrm{mOPD}}, j=k . \Gamma_{\text {diimine }}\right)$. Where $k$ represents the current per mole for interfacial diimine. Surface coverage can be assigned, $\theta=j_{\mathrm{p}} / j_{\mathrm{pmax}}$. The affinity constant for the antibody-antibody interaction is defined as, $K_{\mathrm{a}}=k_{2} / k_{1}$. The Langmuir equation can be linearised as $[15,16]$ :

\section{$\frac{C}{j_{\mathrm{p}}}=\frac{1}{K_{\mathrm{a}} \cdot j_{\mathrm{p} \max }}+\frac{C}{j_{\mathrm{p} \max }}$}

This technique yields a poor linear fit, $R^{2}=0.6965$, particularly at low conjugate concentration where lateral interactions of complexing molecules should be minimal. The $j_{\text {pmax }}$ value calculated by this treatment is $6545 \mathrm{nA} \mathrm{mm}^{-2}$ which is almost 2.5 fold larger than saturation data alluded by the dose-response curve in Figure 8. This outcome would suggest the binding of conjugate to the immunoelectrode is far from its limit. An affinity constant for the conjugate interaction with the immunoelectrode was calculated from the intercept of the Langmuir graph $\left(1 / K_{\mathrm{a}} j_{\mathrm{pmax}}\right), K_{\mathrm{a}}=1.4 \times 10^{5} \mathrm{~mol}^{-1} \mathrm{dm}^{3}$. This value is low for an antibody binding affinity (typically $\left.\geq 10^{8} \mathrm{M}^{-1}\right) .{ }^{16}$ Once more, this could be explained by the crude adsorption model adopted for protein binding and the assumptions made equating the electrochemical parameter, $j_{\mathrm{p}}$, and surface concentration of conjugate.

\subsection{Actin ELISA}

The immunoelectrode response towards actin-G antigen in a double-antibody ELISA was studied by diimine voltammetry. Figure 9 shows typical forms of the immunoelectrode signal after exposure to an actin standard (1000 $\mathrm{n} \mathrm{mL}^{-1}$ ), following incubation with the secondary antibody and anti-antibody peroxidase conjugate. Cathodic shifts in $E_{\mathrm{pc}}$ again appear in these voltammetric measurements which correlate with increasing surface concentration of peroxidase (data not shown). Cyclic voltammetry shows an intense reduction wave with a much diminished oxidation wave in the reverse scan. As peroxidase conjugate accumulates on the immunoelectrode, diimine currents elevate from a baseline $j_{\mathrm{p}}$ measure of $2917 \mathrm{nA} \mathrm{mm}^{-2} \quad\left(0 \mathrm{ng} \mathrm{mL}^{-1}\right)$ to an optimum of $3801 \mathrm{nA} \mathrm{mm}^{-2}\left(100 \mathrm{ng} \mathrm{mL}^{-1}\right)$. Table 2 lists ELISA data for the entire actin standards, $0 \mathrm{ng} \mathrm{mL}^{-1}$ to $1000 \mathrm{ng} \mathrm{mL}^{-1}$. The mean precision realised for the actin assay was $R S D$ $2.7 \%(n=6)$ and $R S D 7.1 \%\left(100 \mathrm{ng} \mathrm{mL}^{-1}\right.$ standard): a further indication of the remarkable stability of the capture antibody layer and therefore the reliability of the physicochemical immobilisation method used in the fabrication of the actin immunoelectrode.

Blank or baseline currents in actin measurements were found higher than those observed in the conjugate adsorption study, circa $2900 \mathrm{nA} \mathrm{mm}^{-2}$, compared to $2685 \mathrm{nA} \mathrm{mm}^{-2}$ (actin, $0.0 \mathrm{ng} \mathrm{mL}^{-1}$ ). The discrepency be- 
Table 2. Actin ELISA data collated for an actin responsive immunoelectrode utilising a double-antibody protocol.

\begin{tabular}{llllllll}
\hline Actin $C(\mathrm{ng} / \mathrm{mL})$ & Actin $j_{\mathrm{p}}\left(\mathrm{nA} \mathrm{mm}^{-2}\right)$ & $n$ & $R S D(\%)$ & Background $j_{\mathrm{p}}\left(\mathrm{nAmm}^{-2}\right)$ & $n$ & $R S D(\%)$ & \left.${\text { Corrected } j_{\mathrm{p}}(\mathrm{nAmm}}^{-2}\right)$ \\
\hline 0 & 2964 & 3 & 8.2 & 47.0 & 4 & 5.0 & 2917 \\
0.1 & 3113 & 5 & 9.6 & 46.2 & 4 & 14.3 & 3067 \\
1 & 3094 & 4 & 9.1 & 48.5 & 4 & 7.6 & 3046 \\
10 & 3401 & 3 & 4.7 & 50.3 & 3 & 35.7 & 3351 \\
100 & 3846 & 4 & 7.1 & 44.8 & 5 & 15.6 & 3801 \\
1000 & 3328 & 4 & 2.5 & 91.6 & 4 & 25.9 & 3236 \\
\hline
\end{tabular}
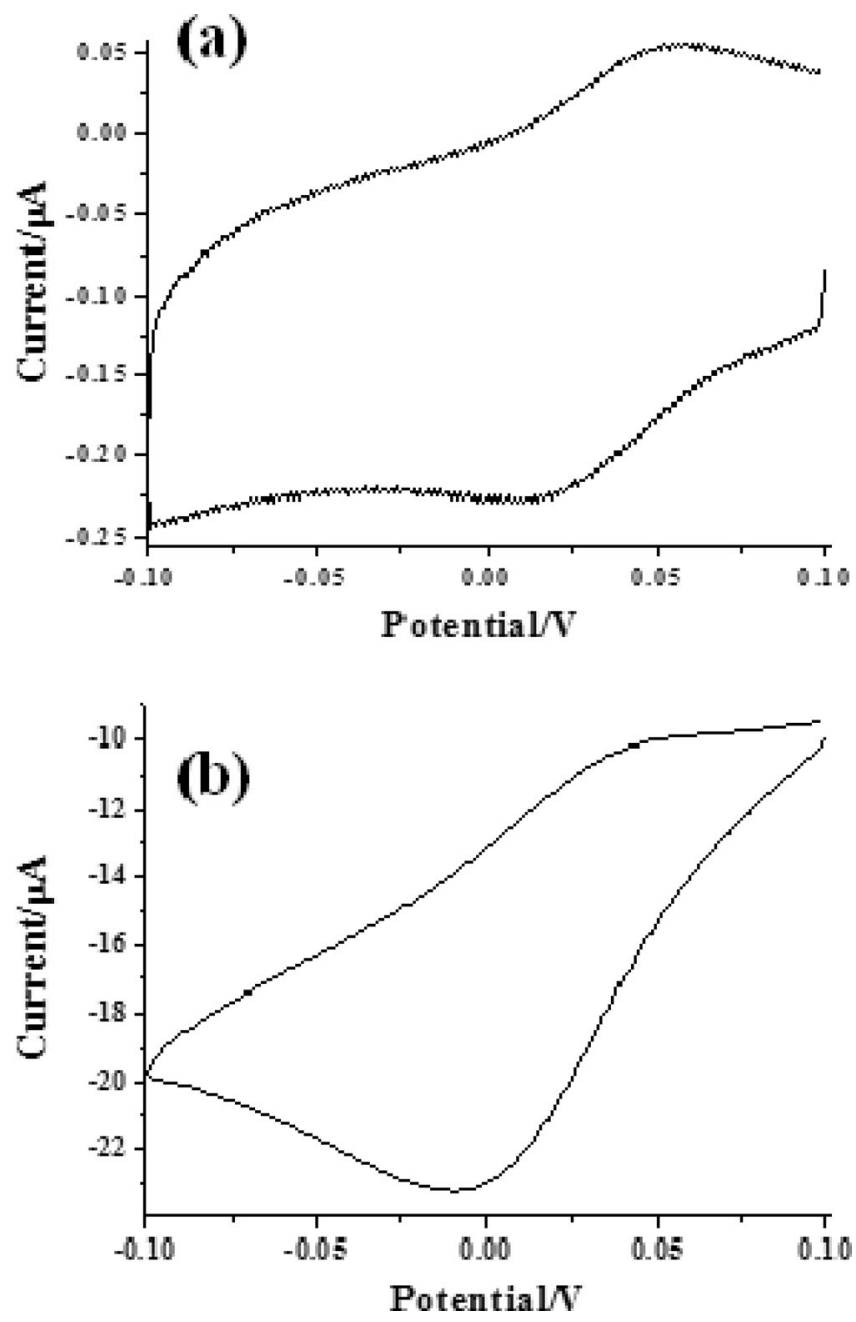

Fig. 9. Cyclic voltammetry response of the actin immunoelectrode to actin antigen $100 \mathrm{ng} / \mathrm{mL}$ : (a) BSA electrode response; (b) actin immunoelectrode. Conditions as for actin assay. ELISA data summary in Table 2.

tween the two data sets may have arisen because the secondary antibody is present only in the actin assay protocol. The conjugate has affinity not only with the immunoelectrode capture antibody, but also through non-specific interactions involving the secondary antibody. A linear-log, $j_{\mathrm{p}}-C$ plot for the immunoelectrode response towards actin concentration illustrates a complex binding pattern, Figure 10. As the surface coverage of actin progresses, diimine currents associated with captured peroxidase gradually elevate above the baseline value. The im-

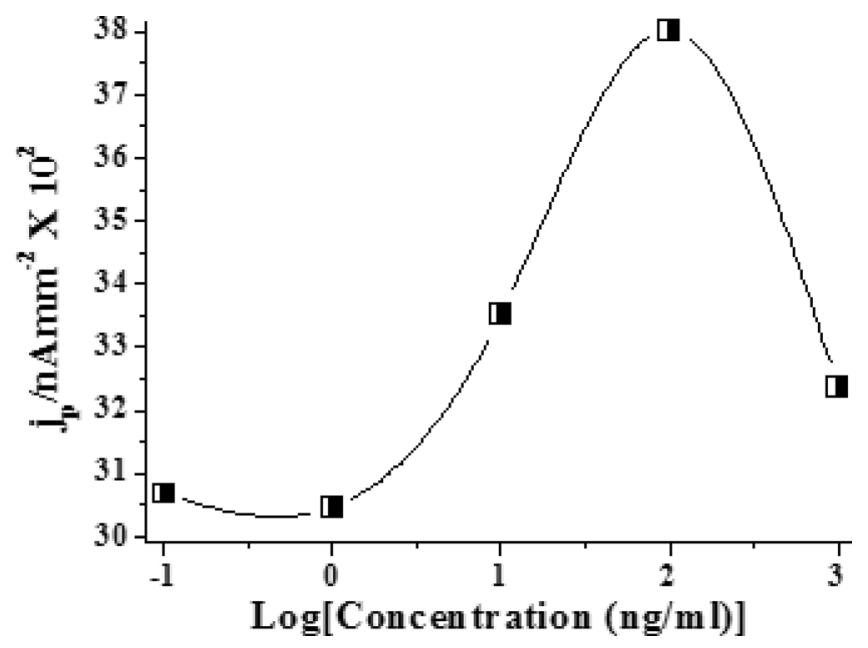

Fig. 10. Response of the immunoelectrode to actin concentration. Plotted as current density, $j_{\mathrm{p}}$ (background corrected) versus actin concentration (logarithmic scale). Data taken from voltammetry measurements cited in Figure 9 and Table 2.

munoelectrode shows little sensitivity at very low levels of actin $\leq 1 \mathrm{ng} \mathrm{mL}^{-1}$, but is increasingly responsive to actin approaching $10 \mathrm{ng} \mathrm{mL}^{-1}$. The data would indicate the detection limit of the immunoelectrode lies somewhere in the range of $1-10 \mathrm{ng} \mathrm{mL}^{-1}$, (sub nM). Analytical sensitivity, $j_{\mathrm{p}} / C\left(1-10 \mathrm{ng} \mathrm{mL}^{-1}\right)$ of the actin immunoelectrode is approximately $34 \mathrm{nA} \mathrm{mm}^{-2} / \mathrm{ng} \mathrm{mL}^{-1}$, or $1424 \mathrm{nA} \mathrm{mm}^{-2} \mathrm{nM}^{-1}$, with measurement precision of $R S D$ $4.7 \%$ for the $10 \mathrm{ng} \mathrm{mL}^{-1}$ actin standard.

The actin immunoelectrode current density reaches an optimum value for the $100 \mathrm{ng} \mathrm{mL}^{-1}$ actin standard, before decreasing at greater actin concentrations. When the immunoelectrode is exposed to the $1000 \mathrm{ng} \mathrm{mL}^{-1}$ actin standard the current density achieved is $3236 \mathrm{nA} \mathrm{mm}^{-2}(n=4$, $R S D 2.5 \%$ ), or $36 \%$ of the $j_{\mathrm{p}}$ peak, alluding to lower binding site availability for the peroxidase conjugate. The antigen dose-response characteristic of the actin immunoelectrode is in fact a consequence of broader macromolecular competitions and steric exclusions at a highly hereogeneous binding surface. Such interactions involve all of the molecules in the ELISA scheme.

\section{Conclusions}

Reported is the construction and characterisation of an actin immunoelectrode assembled from a commercial pencil lead and functionalised with an actin capture anti- 
body. The work illustrates how such polymer-graphite materials offer adequate physisorption of proteins and act as reliable supports for antibodies in electrochemical immunoassay. Data on non-specific interactions at the immunoelectrode is definitive. Polymer-graphite electrodes covered by a layer of BSA molecules and antibody retain immunoactivity directed at the target antigen, actin-G, blocking conjugate physisorption, yet allowing a signalling redox molecule, $o$-benzoquinone-diimine, access to the electrode surface. Conjugate binding experiments provided further detail on the immunoelectrode surface structure. A dose-response characteristic for the conjugate binding directly to the electrode hints at a highly heterogeneous protein layer. The $j_{\mathrm{p}}$ data as a representative measure of $\Gamma$ suggests the immunoelectrode surface is approximately $45 \%$ covered with exposed Fc regions $\Gamma_{\mathrm{Fc}}=j_{\mathrm{pFc}} /\left(j_{\mathrm{pFc}}+j_{\mathrm{pACTIN}}\right)$. Here $j_{\mathrm{pFc}}$ is the plateau value of the current density in conjugate binding assays, while $j_{\text {pACTIN }}$ is the optimum value of $j_{\mathrm{p}}$ in the actin assays. This result has implications for immunoelectrode sensitivity and would infer that most capture antibodies are arranged 'side-on' at the electrode surface.

The actin immunoelectrode was applied to the quantitative measurement of bovine muscle actin at concentrations $\leq 1000 \mathrm{ng} \mathrm{mL}^{-1}(<24 \mathrm{nM})$ following an ELISA methodology involving a double-antibody assay format. The dose-response curve for the assay shows the electrode is most sensitive to actin for concentrations between $1 \mathrm{ng} \mathrm{mL}{ }^{-1}-10 \mathrm{ng} \mathrm{mL}^{-1}$, while displaying a high-dose hook effect towards actin for concentrations $>100 \mathrm{ng} \mathrm{mL}^{-1}$. Hook behaviour would certainly constrain the analytical calibration of the present immunoelectrode. It could be overcome by electrode design changes such as introducing higher surface concentration of capture antibody, or more judicious control of concentrations for the reagent system. Of course the actin immunoelectrode response would greatly improve by altering the ELISA scheme to a more conventional antigen sandwich format.

\section{Acknowledgements}

Immunoassay at the Tip of a Pencil was funded under the Technological Sector Research - Postgraduate Research and Development Skills Programme (PRDSP Strand 1). This research was carried out at the CREATE laboratory, ITT Dublin, Ireland.

\section{References}

[1] M. A. Geeves, K. C. Holmes, Annual Review of Biochemistry 1999, 68, 687-728.

[2] K. S. Forland, T. Forland, S. K. Ratkje, Irreversible Thermodynamics: Theory and Applications, Wiley, Chichester, 1988.

[3] T. Nageh, R. A. Sherwood, B. M. Harris, J. A. Byrne, M. R. Thomas, Inter. J. Cardiol. 2003, 92, 285-293.

[4] W. Sun, K. Jiao, S. Zhang, Talanta 2001, 55, 1211-1218.

[5] K. Aoki, T. Okamoto, H. Kaneko, K. Nozaki, A. Negishi, J. Electroanal. Chem. Interf. Electrochem. 1989, 263, 323-331.

[6] H. Kaneko, A. Negishi, Y. Suda, Electrochem. Soc. Proc. 1997, 97(19), 433-439.

[7] A. Izadyar, Y. Kim, M. M. Ward, S. Amemiya, J. Chem. Edu. 2012, 89, 1323-1326.

[8] M. Ozsoz, A. Erdem, K. Kerman, D. Ozkan, B. Tugrul, N. Topcuoglu, H. Ekren, M. Taylan, Anal. Chem. 2003, 75, 2181-2187.

[9] A. Erdem, P. Papakonstantinou, H. Murphy, Anal. Chem. 2006, 78, 6656-6659.

[10] M. Steinitz, Anal. Biochem. 2000, 282, 232-238.

[11] Y. L. Jeyachandran, J. A. Mielczarski, E. Mielczarski, B. Rai, J. Coll. Interf. Sci. 2010, 341, 136-142.

[12] S. Fornera, P. Walde, Anal. Biochem. 2010, 407, 293-295.

[13] H. Liu, Z. Wang, Y. Liu, J. Xiao, C. Wang, Thermochim. Acta 2006, 443, 173-178.

[14] T. Wangkam, S. Yodmongkol, J. Disrattakit, B. Sutapun, R. Amarit, A. Somboonkaew, T. Srikhirin, Curr. App. Phys. 2012, $12,44-52$

[15] G. M. Barrow, Physical Chemistry, 4th ed., McGraw-Hill, New York, 1979, pp. 731-754.

[16] D. G. Wild, 4th ed., The Immunoassay Handbook: Theory and applications of ligand binding, ELISA and related techniques, Elsevier, Amsterdam, 2013.

Received: August 1, 2014

Accepted: October 5, 2014

Published online: December 8, 2014 